\title{
Extracting paleodust information from peat geochemistry
}

\author{
François De Vleeschouwer ${ }^{1,2}$, M. Ferrat ${ }^{3}$, H. McGowan ${ }^{4}$, H. Vanneste ${ }^{1,2}$ and D. Weiss ${ }^{3}$
}

\section{Peatlands are formidable geochemical archives of atmospheric dust and are increasingly being used to address major paleoclimatic questions. Here, we provide an insight into the recent advances.}

Peatlands are increasingly used as terrestrial archives of atmospheric dust deposition.

Peat records mostly cover the Holocene, although some may extend beyond $10 \mathrm{ka}$ (e.g. Kylander et al. 2007). The global occurrence of peatlands makes them a good alternative for making inter-hemispheric comparisons of paleoclimate when other terrestrial records are not available. Europe, for example, lacks long Holocene atmospheric archives such as ice cores, but it contains widespread peat deposits. Similarly, in the Southern Hemisphere, peatlands provide an opportunity to probe the entire Holocene, a period for which dust records from polar ice and marine cores are generally absent or offer lower resolution.

Peatlands have two key advantages over many other paleoenvironmental archives: they are relatively easy to access and sample and their high accumulation rates allow records of sub-decadal scale to be developed. Ombrotrophic (i.e. atmosphere-fed) peatlands, or bogs, offer the greatest insights into past climate as they only receive input through the atmosphere, such as aerosols and rain, and thus truly reflect local to regional-scale atmospheric conditions (Le Roux et al. 2010; Marx et al. 2009). Minerotrophic (i.e. stream-fed) peatlands, or fens, can also provide valuable information in terms of dust sources (e.g. Kylander et al. 2007; Muller et al. 2008a,b).

Earlier studies on peatland chemistry focused on atmospheric trace metal contamination to reconstruct pollution histories (e.g. Lee and Tallis 1973; Shotyk et al.1998). Today, studies focus more on the paleoclimatic and paleoenvironmental information of the dust trapped in peat. This includes developing tools to assess the integrity of the record (i.e. effects of post depositional element movements or groundwater input), to identify the origin of mineral dust particles and to quantifying flux changes through time.

\section{Flux calculation}

Atmospheric dust fluxes in bogs are reconstructed from the vertical distribution of lithogenic trace elements such as $\mathrm{Ti}, \mathrm{Sc}, \mathrm{Zr}$, $\mathrm{Y}$ or REE (Rare Earth Elements) in bulk peat samples. These elements are not affected by post-depositional processes and do not have a significant anthropogenic source. In addition, it is essential to develop robust chronologies for the peat profiles based, for example, on ${ }^{14} \mathrm{C}$ and ${ }^{210} \mathrm{~Pb}$ dating, and on age modeling that takes into account dating and accumulation rate uncertainties (Blaauw and Christen 2011). Robust chronologies allow dust fluxes to be calculated accurately, and to establish specific tie-points and correlate them to known climate events. Dust flux records have been successfully used to pinpoint abrupt events such as the Younger Dryas (Shotyk et al. 2002; Weiss et al. 2002), the 8.2 ka event (Shotyk et al. 2002; Le Roux et al. 2012), and the Little Ice Age (De Vleeschouwer et al. 2009). Furthermore, with good knowledge of the geochemical properties of potential dust source areas it is possible to distinguish distal from local (sub-)catchment sources, and apportion their contributions through time, thereby providing insight into regional scale environmental change (Marx et al. 2009, 2010).

\section{Using dust records in modeling}

The deposition rates determined from peat records offer a tool for validating atmospheric circulation model simulations, which in turn provide a platform for investigating the interactions between the atmospheric dust cycle and environmental change. Model validation of aerosol components is, however, still limited by the scarcity of past dust flux records.

A regional atmosphere-chemistry/aerosol climate model (REMOTE) has recently been successfully applied to simulate dust emissions and transport from the major Chinese deserts to its subsequent deposition over the Central Tibetan Plateau (Ferrat el al. 2013). This study showed that numerical modeling has the potential to reveal more about past and present dust cycles. The study also concluded, however, that further refinement of the dust and soil surface property parameterization is in particular needed in order to improve the climate model.

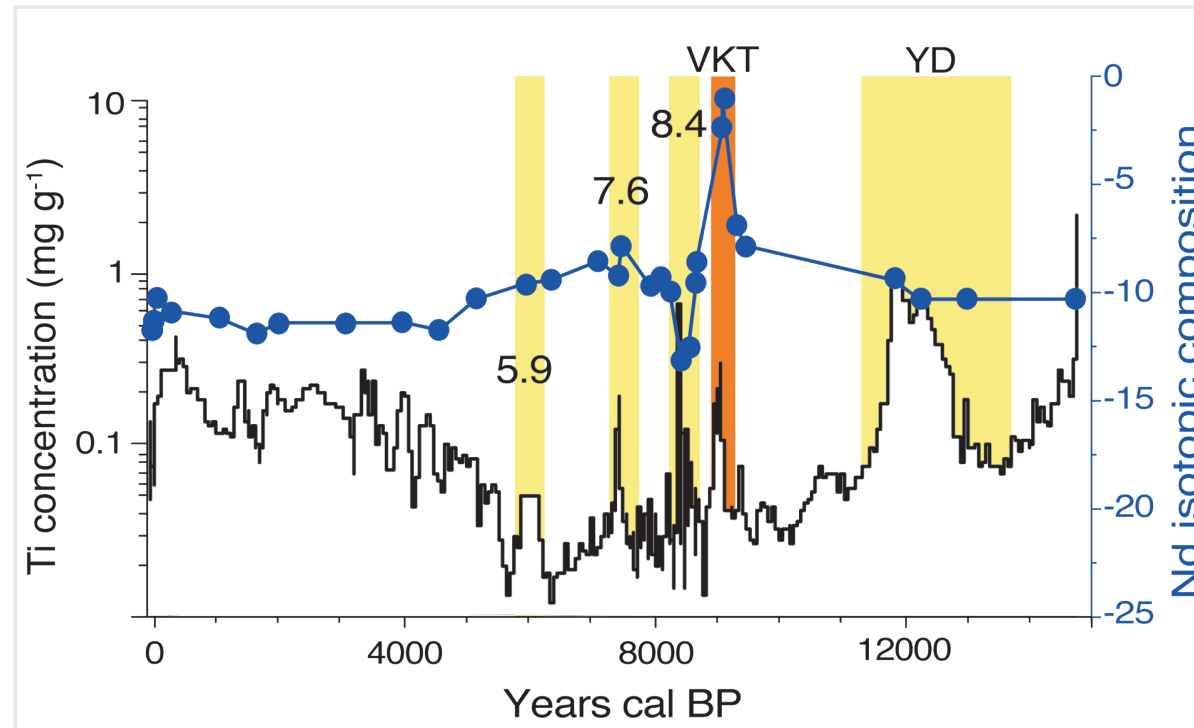

Figure 1: Ti concentration and Nd isotopic composition ( $\varepsilon N d$ ) in a bog profile in Switzerland. The Younger Dryas (YD) is characterized by an increase in local dust input, reflected by high Ti concentrations. Early Holocene Vasset-Kilian eruptions (VKT) in the French Massif Central result in high $\varepsilon N d$. Saharan dust input is identified by negative $\varepsilon N d$ around $8.4 \mathrm{ka}$. The progressive desertification of the Sahara during the Holocene decreases $\varepsilon N d$ progressively from 7.5 to $3.5 \mathrm{ka}$ cal BP, when local erosion becomes dominant. The two dust peaks (yellow bars) at 5.9 and 7.6 ka remain unexplained. Modified from Le Roux et al. 2012. 


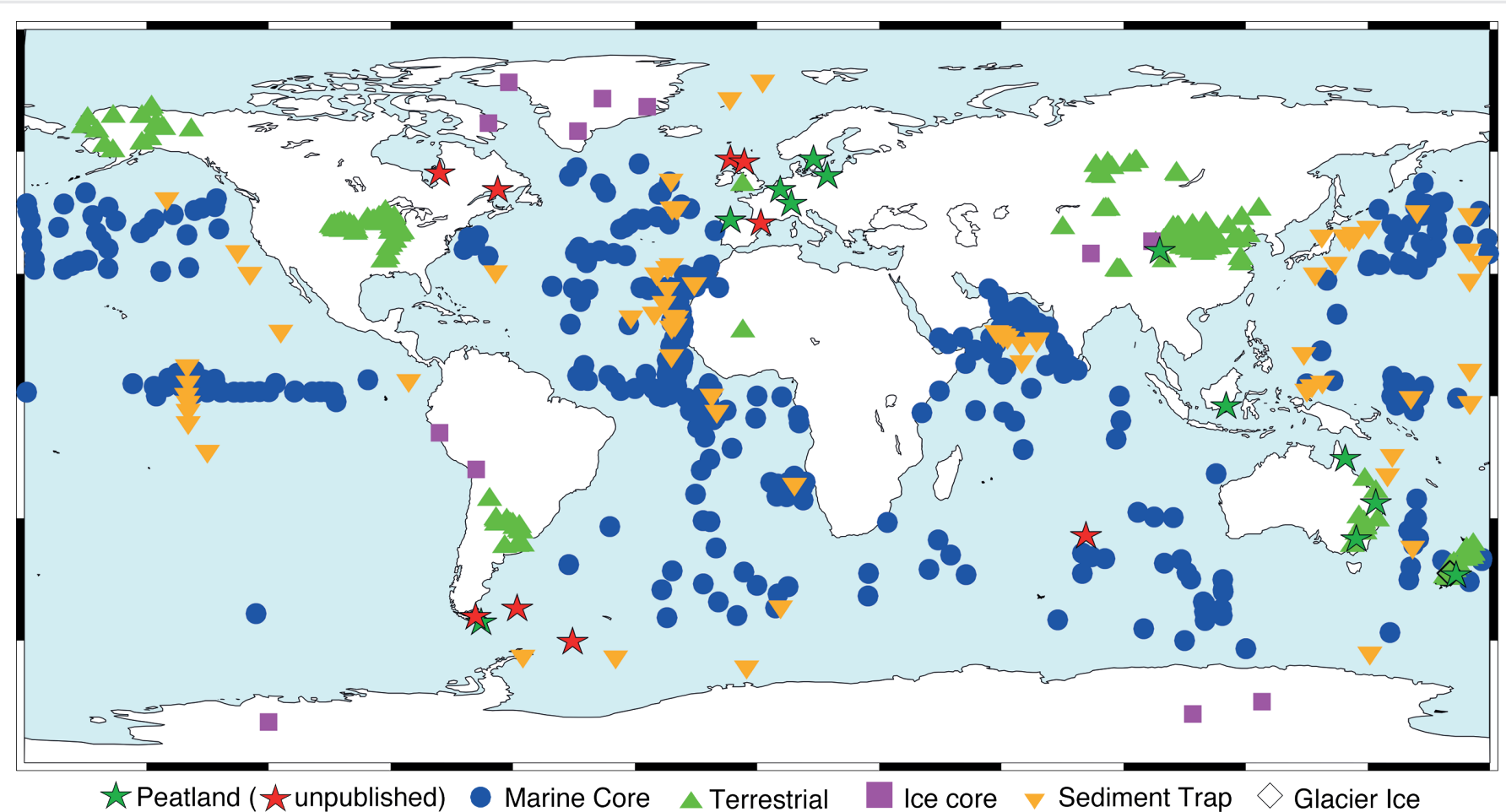

Figure 2: World coverage of dust records in peat, including already published peatland records (green stars) and ongoing works (red stars). Map drawn from Kohfeld and Tegen (2007), Mahowald et al. (2006) and Kohfeld and Harrison (2001).

Another opportunity of data-model symbiosis lies in quantifying abrupt changes (or change points). The dust deposition record is normally represented as a function of depth or time. Trans-dimensional Markov chain Monte Carlo analysis has recently been explored to infer probability distributions on the number, position and age of change points, the mean distance between change points, and the noise variance associated with each dust record (Gallagher et al. 2011; Kylander et al. 2013). Simulating noise in dust records from bogs or ice cores can complement the observational information. Noise estimates of proxy records are normally limited to the measurement uncertainty, and in most cases it is not practical to repeat sampling and measurements to experimentally assess noise. Gallagher et al. (2011) analyzed several sets of geochemical dust data from peat cores taken from Australia, Sweden and Tibet. They showed that their model-based analyses are consistent with those previously inferred qualitatively from independent data and interpretations. Moreover, this approach provides quantitative estimates of the relative probability of the inferred change points, allowing an objective assessment of the significance of each change.

\section{Sources}

Lead isotopes were first used to identify sources of anthropogenic and natural dust in bogs (Shotyk et al. 1998). This opened a field of investigation aimed at developing proxies that better constrain the relative contributions of local and regional dust sources to peat deposits. However, lead has been emitted by anthropogenic activities for more than 5000 years (Nriagu 1983). This has limited the potential of lead as a natural dust tracer for the Holocene and has resulted in uncertainty in dust provenance reconstructions (Kamber et al. 2010).
In order to define the provenance of dust with greater certainty, other geochemical tracers are increasingly used. Coupling REE and $\mathrm{Pb}$ isotopes or lithogenic elements allows us to determine shifts between wet and dry climate (Kylander et al. 2007), to discriminate local from distal dust (Marx et al. 2009), and to reconstruct wind strength and changes in atmospheric circulation (Marx et al. 2011). In Europe, where Holocene atmospheric archives are rare, Le Roux et al. (2012) combined lithogenic elements, REE and $\mathrm{Nd}$ isotopes to reconstruct the dust flux and sources over the last 14 ka from a bog in Switzerland (Fig. 1). In this study, the interplay between climate and natural dust draws a complex picture of the Holocene dust sources, which are the Sahara desert, volcanism in France, and local erosion. Dust during the Younger Dryas dominantly originated from strong local erosion and minera input, while during early Holocene volcanic eruptions and abrupt Saharan dust input around $8.4 \mathrm{ka}$ BP were the main sources. In addition, the progressive desertification of the Sahara, already suggested by Kylander et al. (2005) using lead isotopes in a Spanish peat core, was identified through a progressive increase in $\mathrm{Ti}$ and a shift in $\varepsilon \mathrm{Nd}$ from 8 to $4 \mathrm{ka}$ BP. With the same approach using REE and Nd isotopes, Allan et al. (2013) identified increased dust fluxes during cold periods and large supplies from distal (Saharan dust and Icelandic volcanism), regional (European Loess) and local sources during the Holocene.

\section{Outlook}

As an increasing number of studies have shown, the geochemical separation of dusts in peat and their provenance offers the prospect of unmatched insight into paleo-atmospheric circulation, its variability and the environmental consequences, primarily from synoptic to macro-scales, and associated environmental changes (McGowan et al 2008; Petherick et al. 2009). Accordingly, using dusts as tracers of paleoclimate provides an opportunity to calibrate and validate climate models. Efforts are now being made to refine the spatial coverage of peat dust records from the high latitudes to the tropics (Fig. 2) and extend the records back into the Quaternary. Peat researchers are now focusing on covering areas where dust records are lacking such as Canada, India and the Southern Hemisphere (Patagonia, Tierra del Fuego, South Africa, Falkland Islands, Amsterdam Island).

\section{AFFILIATIONS}

${ }^{1}$ EcoLab (Laboratory for Functional Ecology and

Environment), Université de Toulouse, INP, UPS, ENSAT, Castanet Tolosan, France

${ }^{2}$ EcoLab, CNRS, Castanet Tolosan, France

${ }^{3}$ Department of Earth Sciences and Engineering, Imperial College London, London, UK.

${ }^{4}$ Climate Research Group, The University of Queensland, Brisbane, Australia

\section{CONTACT}

François De Vleeschouwer: francois.devleeschouwer@ ensat.fr

\section{REFERENCES}

\section{Full reference list under:}

www.pages-igbp.org/products/magazine/ref2014_2.pdf Allan M et al. (2013) Clim Past 9: 2285-2298

De Vleeschouwer F et al. (2009) Holocene 19: 625-637

Ferrat M et al. (2012) Geochim Cosmochim Acta 91: 7-31

Le Roux G et al. (2012) Geology 40: 335-338

Marx SK et al. (2011) Quat Sci Rev 30: 3290-3305 